\title{
A High-speed Tissue Homogenizer
}

\author{
By S. J. FOLLEY AND S. C. WATSON \\ National Institute for Research in Dairying, University of Reading
}

(Received 14 August 1947)

This paper describes a machine designed primarily for preparing uniform dispersions or homogenates of animal tissues in aqueous media for enzyme studies. It has proved invaluable in studies of the arginase and alkaline phosphatase of tissues such as liver, kidney and mammary gland (Folley \& Greenbaum, $1946,1947)$, particularly in experiments involving estimation of the enzymes in tissues taken from groups of animals killed on the same day where the question of the time required for preparing tissue extracts or homogenates may be crucial.

The technique of Potter \& Elvehjem (1936) for preparing homogenates of small fragments of tissue for investigation of the effects of dilution on respiratory enzyme systemms was not felt to be suitable for our purpose, which was to obtain estimates of the concentration and total amount of certain watersoluble hydrolytic enzymes in whole organs of the rat. Even though the apparatus of Potter \& Elvehjem might well be built on a scale sufficient for $50-60 \mathrm{ml}$. of fluid, it seemed clear that our work required a relatively robust, yet 'precision' machine, easy to use and capable of dealing rapidly and reproducibly with fair-sized masses of perhaps tougher tissue than one might expect could be easily and routinely handled with the homogenizer of Potter \& Elvehjem.

How far our apparatus will be applicable to making tissue dispersions for the study of other tissue enzyme systems and perhaps hormones remains to be seen. Preliminary trials suggest that it may prove useful for homogenizing plant materials, textile fibres, etc.

\section{DESCRIPTION OF HOMOGENIZER}

The machine is illustrated in Figs. 1 and 2 . It incorporates the principle of rotating knives, a principle which had already been embodied in the Waring Blendor. The homogenization is carried out in the Pyrex glass vessel $A$, consisting of a tube blown at one end into a bulb of $100 \mathrm{ml}$. capacity, the walls of which are fluted in such a way that the cross section through its greatest diameter is as shown in the lower drawing of Fig. 2. This glass vessel is held firmly and quite centrally inside a cylindrical metal container $B$ by the accurately turned fibre collar $C$ and the rubber ring $D$, the centre of which is shaped to the bottom of the bulb.
Three phosphor-bronze springs $E$, fixed to the inner wall of the container and spaced equidistantly, help to centre the bulb and hold it firmly in position. Vibration during running is minimized by rubber studs inserted into the inner and outer edges of the fibre collar, and projecting slightly so that they press against the outer surface of the glass tube and the inner surface of the metal container respectively.

The tissue to be homogenized is weighed, cut into pieces about the size of a pea with scissors, and placed in the glass vessel together with a suitable volume of the chosen dispersion fluid (saline, Ringer, etc.). The machine works best with a total volume of tissue and fluid of about $50 \mathrm{ml}$., but in exceptional cases volumes as small as $30 \mathrm{ml}$. or as high as $60 \mathrm{ml}$. have been used. Larger volumes cannot be used with vessels of the present dimensions because of the danger of splashing when the machine is running at speed.

The container assembly is put together as shown in the sectional elevation in Fig. 2, and inserted through the collar $F$ which it fits accurately. A small dowel on the outside of the container passes up through a slot in the inner face of the collar, the width of which undergoes a slight but gradual increase for about 2 in. in an anti-clockwise direction from the slot, so that on turning the container through about an eighth of a circle with the dowel resting on the top edge of the collar, the flange at the base of the container is brought up tight against the bottom of the collar. The set screw $G$ is then tightened to hold the container immobile during the run. The inside of the container is strengthened at the bottom by a metal ring $H$ to withstand the pressure of the set screw.

The Universal motor $J$ revolves at 12,000 15,000 r.p.m. To its shaft is directly coupled a stainless steel spindle carrying at its lower end four accurately balanced stainless steel knives $K$, two of which are horizontal and two project upwards and downwards respectively at an angle of $45^{\circ}$. Thus a considerable proportion of the interior space of the bulb is swept by the revolving knives, which are of such a length as to pass easily down the neck of the dispersion vessel. The length of the spindle is such that when the apparatus is assembled the two horizontal knives lie below the plane of the greatest diameter of the bulb ( $A-A$ in Fig. 2). 
A stainless steel sleeve $L$ attached to the spindle overlaps the tapered end of the motor casing $M$, thus preventing oil from the motor bearings creeping down the shaft. At the bottom of the sleeve is fixed a fibre disk $N$, of diameter slightly less than the internal diameter of the neck of the dispersion vessel, to prevent loss of fluid due to splashing. This, however, does not occur if due precautions are taken in starting up.

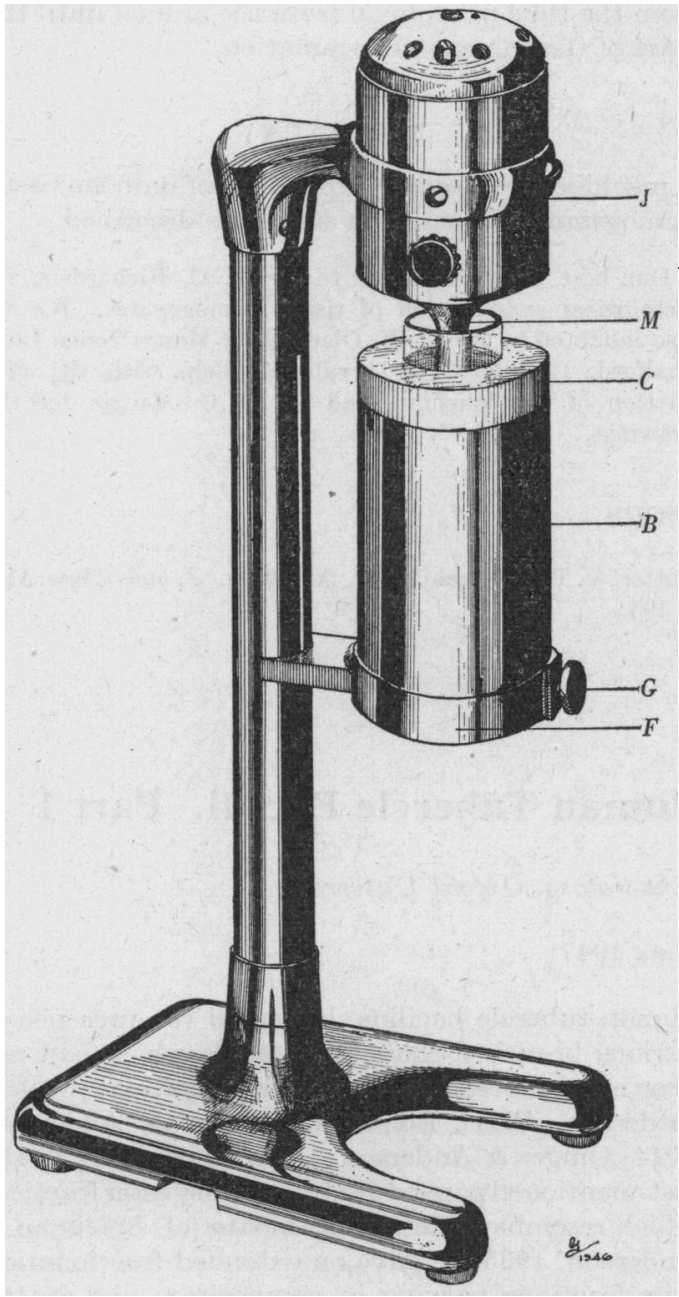

Fig 1. Perspective view of homogenizer.

A suitable sliding resistance is used for starting, and in order to prevent splashing, it is necessary to start slowly, and run at a reduced speed for some seconds until it is obvious from the sound coming from the interior of the dispersion vessel that the lumps of tissue have been largely broken down. Only then is the motor taken up to full speed. If this precaution is not observed the whirling mass of tissue temporarily conglomerated round the knives would tend to force the fluid out of the dispersion vessel. The fluted shape of the bulb is necessary to offer resistance to the rotation of the fluid and to throw it and the tissue into the knives.
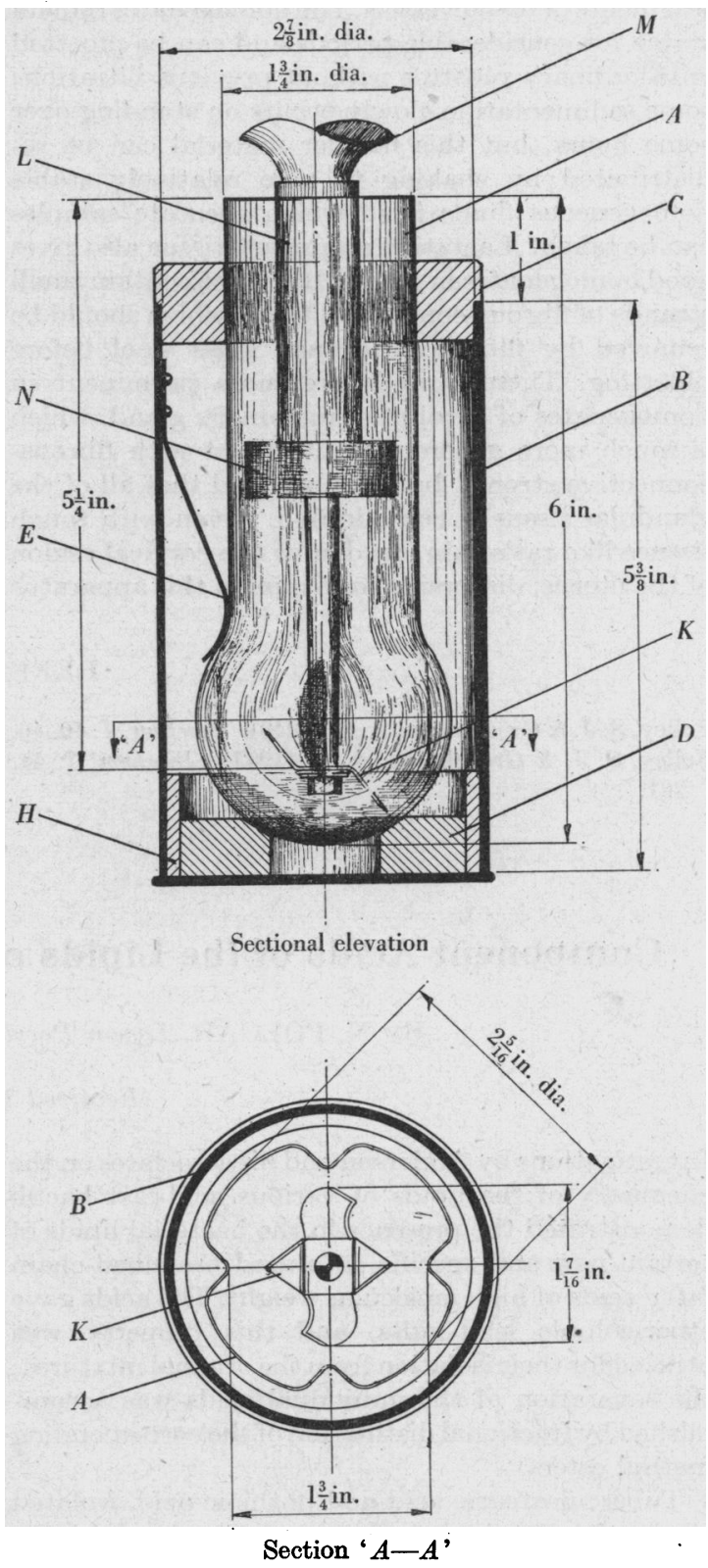

Fig. 2. Sectional scale drawings showing details of dispersion vessel assembly.

Tissues like liver and kidney are uniformly dis persed with the greatest of ease. Stained smears of such homogenates consisted merely of amorphous material quite unrecognizable as belonging to the 
organ in question. There were scattered deformed nuclei present but no clear cellular outlines. Occasionally somewhat larger irregular masses could be recognized as containing connective tissue and fragments of blood vessels. The homogenates remain stable for considerable periods and can be pipetted with ordinary pipettes without previous filtration; some sedimentation slowly occurs on standing over some hours, but this heavier material can be redistributed by shaking to give relatively stable homogeneous fluids from which accurate samples can be taken. Lactating mammary tissue also gives good homogenates in 5 min., but these contain small strends of fibrous-connective tissue which should be removed by fltration through glass wool before pipetting. These strands are more prominent in homogenates of involuting mammary gland, which is much more generously interlaced with fibrousconnective stroma, but it is believed that all of the glandular tissue is comminuted. Even with tough tissues like rat's skin, tendon or the cervical region of the uterus, dispersion for $5 \mathrm{~min}$. in this apparatus produces a surprising degree of comminution. These and many other tissues, which the machine can handle with ease, present a formidable proposition when ground with sand in a pestle and mortar.

The contents of the dispersion vessel tend to warm up during homogenization, and if necessary can be cooled by packing the space between the dispersion vessel and the container with ice. Alternatively, it is easy to maintain the tissue at body temperature from the time of removal from the animal until the start of the enzyme determination.

\section{SUMMARY}

A machine for the easy preparation of uniform tissue homogenates for enzyme studies is described.

Our best thanks are due to $\mathrm{Mr}$ K. C. Richardson for histological examination of tissue homogenates. We are also indebted to $\mathrm{Mr} \mathbf{K}$. W. Gladwell of Messrs Nelco Ltd., Shalford, Guildford, for invaluable help with the production of the machine, and to Mr C. Machin for the drawings.

\title{
- REFERENCES
}

Folley, S. J. \& Greenbaum, A. L. (1946). Biochem. J. 40, 46. Folley, S. J. \& Greenbaum, A. L. (1947). Biochem. J. 41, 261.
Potter, V. R. \& Elvehjem, C. A. (1936). J. biol. Chem. 114, 495.

\section{Component Acids of the Lipids of Human Tubercle Bacilli. Part 1}

\author{
By N. POLGAR, Dyson Perrins Laboratory, Oxford University
}

(Received 10 June 1947)

Investigations by Anderson and his associates on the chemistry of the lipids of various acid-fast bacilli demonstrated the presence in the bacterial lipids of certain new and specific saturated branched-chain fatty acids of high molecular weight. The acids gave ether-soluble lead salts, and this property was utilized for their isolation from the original mixtures; the separation of the individual acids was accomplished by fractional distillation of the corresponding methyl esters.

Tuberculostearic acid and phthioic acid, isolated by the above procedure from the acetone-soluble fat of the human type tubercle bacillus, strain H-37, appeared to be characteristic components of the lipids of human tubercle bacilli, although the composition of the lipids was found to vary from strain to strain (cf. Crowder, Stodola, Pangborn \& Anderson, 1936). More recently studies of cell residues from the preparation of the purified tuberculin protein PPD, derived from an unidentified strain of the human tubercle bacillus, indicated the presence of various branched-chain fatty acids which had not been encountered in previous investigations (Peck \& Anderson, 1941; Edens, Creighton \& Anderson, 1944; Ginger \& Anderson, 1944). According to the last-mentioned paper a dextrorotatory ester fraction, which resembled methyl phthioate (cf. Spielman \& Anderson, 1935-6), gave on extended fractionation four fractions varying in composition and in the magnitude of optical rotation.

Investigations in this laboratory (Polgar \& Robinson, 1945) led to the synthesis of a number of methyl-substituted long-chain acids, of which 3:13:19-trimethyltricosanoic acid exhibited properties resembling those of phthioic acid. Biological studies by Dr C. E. Coulthard, of the Research Department of Boots Pure Drug Co. Ltd., and Dr J. Ungar, of Glaxo Laboratories Ltd., indicated that the synthetic acid produces in experimental animals lesions similar to the tubercle, the characteristic 